\title{
High prevalence of fecal carriage of extended-spectrum $\beta$-lactamase-producing Escherichia coli and Klebsiella pneumoniae in a pediatric unit in Madagascar
}

\author{
Todisoa Andriatahina ${ }^{\dagger 1}$, Frédérique Randrianirina ${ }^{\dagger 2}$, Eliosa Ratsima Hariniana², Antoine Talarmin², \\ Honoré Raobijaona1 ${ }^{1}$ Yves Buisson ${ }^{3}$ and Vincent Richard*2
}

\begin{abstract}
Background: Extended-spectrum $\beta$-lactamase (ESBL)-producing Enterobacteriaceae have spread worldwide but there are few reports on carriage in hospitals in low-income countries. ESBL-producing Enterobacteriaceae (ESBL-PE) have been increasingly isolated from nosocomial infections in Antananarivo, Madagascar.

Methods: we conducted a prevalence survey in a pediatric unit from March to April 2008 Patient rectal swabs were sampled on the first and the last day of hospitalization. Medical staff and environment were also sampled. Rectal and environmental swabs were immediately plated onto Drigalski agar supplemented with $3 \mathrm{mg} / \mathrm{liter}$ of ceftriaxon.

Results: Fecal carriage was detected in $21.2 \%$ of 244 infants on admission and $57.1 \%$ of 154 on discharge, after more than 48 hours of hospitalization $(p<0.001$ ). The species most frequently detected on admission were Escherichia coli and Klebsiella pneumoniae (36.9\%), whereas, on discharge, K. pneumoniae was the species most frequently detected (52.7\%). ESBL-associated resistances were related to trimethoprim-sulfamethoxazole (91.3\%), gentamicin (76.1\%), ciprofloxacin (50.0\%), but not to amikacin and imipenem. The increased prevalence of carriage during hospitalization was related to standard antimicrobial therapy.
\end{abstract}

Conclusion: The significant emergence of multidrug-resistant enteric pathogens in Malagasy hospitals poses a serious health threat requiring the implementation of surveillance and control measures for nosocomial infections.

\section{Background}

New classes of enzymes conferring resistance to $\beta$-lactam antibiotics have emerged over the last few decades, due to antibiotic selection pressure; most alarming are the extended spectrum $\beta$-lactamases (ESBLs) produced by enteric pathogens that have spread worldwide since their first description in 1983 [1]. Typically, ESBLs hydrolyze third generation cephalosporins and aztreonam, but not carbapenems, and are inhibited by clavulanic acid and tazobactam [2]. ESBL-producing pathogens frequently exhibit plasmid-encoded multidrug resistance. Therefore, antibiotic therapy for treating these infections is limited

\footnotetext{
* Correspondence: vrichard@pasteur.mg

2 Institut Pasteur, Antananarivo, Madagascar

+ Contributed equally

Full list of author information is available at the end of the article
}

to a small number of expensive drugs. As a result of mutations, more than 200 types of ESBLs are currently described in various species of the Enterobacteriaceae family and other non enteric organisms, such as Pseudomonas aeruginosa and Acinetobacter sp. TEMand SHV-type $\beta$-lactamases, mainly produced by Klebsiella pneumoniae, have spread throughout hospital settings, and CTX-M enzymes, mainly produced by Escherichia coli, have become predominant in the community $[3,4]$.

Since the 1990s, nosocomial outbreaks due to ESBLproducing Enterobacteriaceae (ESBL-PE) have been increasingly reported worldwide, especially in developed countries [5].

In hospital settings, intestinal carriage is the main reservoir of these organisms. The gut colonization of inpa- 
tients is associated with a high risk for developing self and cross infections due to ESBL-producers, especially in long-term care units. Dissemination of ESBL-producing clones results from the movement of patients between various units of the same hospital, but also between hospitals, nationally or internationally [6,7]. In low-income countries, prevalence studies on the carriage of ESBLproducing Gram negative bacilli (GNB) are scarce, whereas the burden of linked infections is increasing due to an absence of expensive second-line antibiotics [8]. A facility-based study on neonatal sepsis in India showed that $50 \%$ of causative GNB were ESBL-PE [9]. Few studies have evaluated fecal carriage during non outbreak situations. Patients colonized at admission can nevertheless introduce the pathogen into hospital units [4].

ESBL-PEs in Madagascar were initially isolated between 2005 and 2006 from community-acquired urinary tract infections [10]. They were then isolated during an epidemic that occurred in two pediatric units in 2006; more recently, ESBL-PEs have been isolated from several infections acquired in various surgical and intensive care units of Antananarivo [11].

This study, conducted in a pediatric department of a large teaching hospital in Antananarivo, aimed to assess the levels of ESBL-PE carriage among hospitalized infants -- on admission and on discharge -- and to determine the risk factors for colonization and infection.

\section{Methods}

\section{Design of the study}

Patients $<15$ years of age hospitalized in the pediatric unit of Befelatanana hospital in Antananarivo were enrolled, after receiving parental consent, in a cohort study from March to April 2008. The unit has a capacity of 22 rooms and 105 beds managed by a staff of 15 physicians, 22 nurses and 15 employees. For each patient, the demographic characteristics (age, gender...), medical history (prior hospitalization, prior invasive devices used...), antibiotic therapies, diagnosis on admission and discharge were recorded. Patient rectal swabs were sampled on the first and the last day of hospitalization. Rectal swabs were also sampled among voluntary medical staff during the same period. Moreover, each week, 20 environmental sites (table, sink, stethoscopes...) were sampled in the four care rooms of the unit.

\section{Laboratory methods}

Rectal and environmental swabs were immediately plated onto Drigalski agar supplemented with $3 \mathrm{mg} /$ liter of ceftriaxone. The plates were forwarded to the Institut Pasteur of Madagascar within 4 hours for 24- to 48-hour incubation at $37^{\circ} \mathrm{C}$. All GNB isolates were identified by Gram staining, and by API 20E and API 20NE system (bioMérieux, Marcy l'Etoile, France). The isolates were then screened for ESBL production using both the resistance phenotype and the double-disk synergy test using conventional combination: cefotaxime, ceftazidime, ceftriaxone and amoxicillin-clavulanic acid [2,12]. The organisms were considered to be producing ESBL when the zone of inhibition around any of the expanded-spectrum cephalosporin discs showed a clear-cut increase towards the clavulanic acid disc. For E cloacae strains, this was confirmed by the double disc potentiation test using a cefepime and clavulanic disc. Phenotypic disc confirmatory test was performed as recommended by the Clinical and Laboratory Standards Institute (CLSI -2005).

Antibiotic susceptibility was tested by the standard disk diffusion method with OSIRIS system (Biorad, Marne la Coquette, France) on Mueller-Hinton agar, as recommended by the Antibiogram Committee of the French Microbiology Society (ACFMS) for the characterization of ESBLs [3]. Amoxicillin, ticarcillin, gentamicin, tobramycin, amikacin, imipenem, nalidixic acid, ciprofloxacin, cotrimoxazole were also tested to determine the resistance patterns of the isolates.

\section{Statistical analysis}

Data entry and analysis were performed with Statistica Software, version 5.5 (Statsoft Corporation, OK, USA). The Chi-square test and Fisher's exact test were used for univariate analysis, with the ANOVA and Kruskall Wallis tests used for comparison of medians. P-values $<0.05$ were considered to be statistically significant. Explanatory variables associated with a p-value less than 0.20 were analyzed by logistic regression to investigate the confounding factors.

\section{Ethical clearance}

The study was approved by the Ministry of Health and the National Ethics Committee of Madagascar. Informed consent was obtained from at least one parent of each child hospitalized before enrolment.

\section{Results}

\section{Hospital characteristics with respect to patients}

\section{Prevalence of ESBL-PE carriage}

Patients Thirty-seven patients were already hospitalized at the start of the study. For these patients, the sex ratio (male/female) was 1.1 and the mean age was 53.1 months (95\%CI: 33.3-73.0). Twenty patients were infected with ESBL-PE (54.1\%), particularly $K$. pneumoniae $(\mathrm{n}=11)$ and E. $\operatorname{coli}(\mathrm{n}=8)$.

From March 10 to April 11, 281 patients were admitted to the pediatric unit. Consent was not obtained for 22 patients (7.8\%). Overall, of a possible 259 patients, 15 patients $(5.8 \%)$ were not included, as they were admitted to the hospital on the last day of the prospective study. 
Of the 244 patients that were included in the cohort, 90 (36.8\%) could not be sampled on discharge for various reasons: $17(18.8 \%)$ died during hospitalization, 19 (21.1\%) left the unit without medical advice and 54 (60.0\%) were hospitalized for less than $48 \mathrm{~h}$. Rectal swabs were collected for 154 (63.1\%) patients on discharge.

Cohort (244 patients) characteristics included a sex ratio of 1.25 , a mean age of 38.3 months (95\%CI: 83.1 95.5). For all the patients included and discharged before the end of the study, the mean length of hospital stay was 5.7 days (95\% CI: 5.2-6.2). Main admitting diagnoses included respiratory (31.5\%), infectious (20.9\%), digestive (12.3\%) and nutritional disorders (15.2\%). On admission, none diagnosed infection was in relation with ESBL-producing microorganism. A total of 54/244 patients (22.1\%) were detected as ESBL-PE carriers on admission, and 88/ 154 (57.1\%) were ESBL-PE carriers on discharge (p-value for trend $<0.001)$. Among the ESBLE-PE carriers on admission $(\mathrm{n}=54)$, 34 could be sampled on discharge. Among the 31 that were still ESBL-PE carriers; 12 (38.7\%) harbored a different organism. On discharge among the 120 sampled patients who were not carriers on admission, 57 (47.5\%) were detected as ESBL-PE carriers (Figure 1).

Carriage rates on admission and discharge did not differ according to the age groups (table 1), but the relative risk of hospital acquisition was significantly higher in the 5-9 year-old group ( $\mathrm{RR}=6.1$ [95\%CI: 1.9-19.4] ).

Medical Staff Among the medical staff (Table 2), 39 of 52 individuals $(75.0 \%)$ agreed to participate in the study. ESBL-PE, E. coli $(\mathrm{n}=9)$ and K. pneumoniae $(\mathrm{n}=9)$, were detected in the rectal swab cultures from 19 medical staff (48.7\%). Carriage rates did not differ according to the period of the study.

Environmental sample At least one isolate of ESBL-PE was detected in each room sampled during the study. Of the 13 positive samples (Table 2), the main species were K. pneumoniae $(\mathrm{n}=5)$, Enterobacter cloacae $(\mathrm{n}=4)$ and

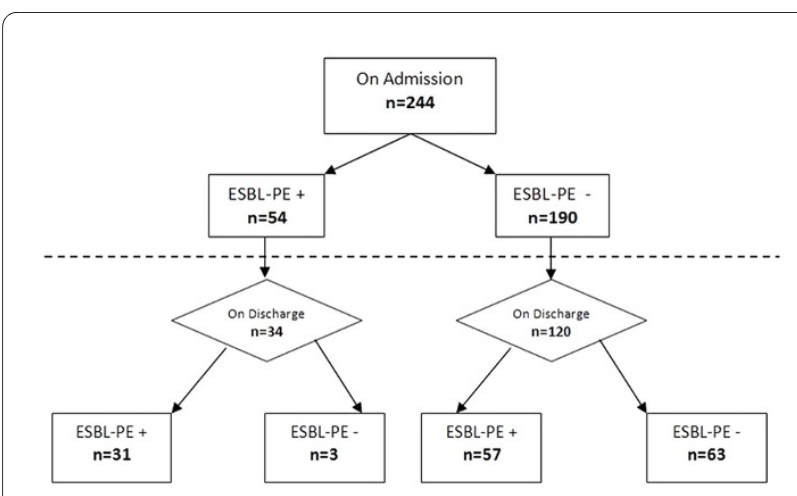

Figure 1 Included patients distribution according to ESBL-PE carriage status on admission and on discharge.
E. $\operatorname{coli}(\mathrm{n}=4)$. K. pneumonia were detected in each care room, E.Coli and E. Cloacae in three of the four care rooms. No ESBL-PE isolate was detected during the second week of the study.

\section{Characteristics of ESBL-PE isolates}

At all 233 ESBL-PE isolates were found: K. pneumoniae (47.2\%), E. coli $(32.2 \%)$ E. cloacae (12.0\%) and other enterobacteriaceae (8.6\%) (Table 2).

On admission, E. coli and K. pneumoniae was the most frequent ESBL-PE identified (36.9\%, 24/65), whereas $K$. pneumoniae was the predominant species on discharge $(52.7 \%, 58 / 110)$, in patients already hospitalized at the start of the study $(55 \%, 11 / 20)$, in medical staff $(45.0 \%, 9 /$ $20)$, in environment $(38.5 \%, 5 / 13)$ and in nosocomial infection $(60.0 \%, 3 / 5)$ (Table 2$)$.

All isolates showed similar resistance patterns. All were susceptible to imipenem and amikacin with cross-resistance to trimethoprim-sulfamethoxazole (91.3\%), gentamicin (76.1\%) and ciprofloxacin (50.0\%). $K$. pneumoniae isolates were significantly less resistant to ciprofloxacin than $E$. coli isolates ( $34.5 \%$ vs $68.4 \%$; p-value $<0.001)$.

Community and hospital acquired strains had the same resistance profile (Table 3 ).

\section{Risk factors for ESBL-PE carriage}

In univariate analysis, significant risk factors for ESBL-PE carriage on admission were prior hospitalization, use of invasive devices in the last 30 days, and infection upon admission (Table 4). In multivariate analysis, four variables were first included in the model: Patient origin, prior hospitalization, use of invasive devices in the last 30 days, infection upon admission. Using backward stepwise procedure, prior hospitalization in the last 30 days (adjusted OR $=7.4$ [95\%CI: 2.9-18.3]) was the only independent risk factor for ESBL-PE carriage.

Significant risk factors for ESBL-PE hospital acquisition in univariate analysis were antibiotic therapy and intramuscular injections (Table 5). Ages of patients did not differ between ESBL-PE carriers (mean: 34.2 months) and non carriers (mean: 39.6 months). In multivariate analysis, five variables were first included in the model: antibiotic therapy, intracranial catheter, brachial catheter, intramuscular injections and care rooms used. After backward stepwise procedure, antibiotic therapy (adjusted OR $=4.1$ [95\%CI: $1.8-9.4]$ ) was the only independent risk factor for ESBL-PE acquisition.

During hospitalization, $64.2 \%$ of the patients were treated by antibiotic therapy. The average number of antibiotics prescribed by patient was 1.2 (95\%CI: 1.0-1.4). For patients with ESBL-PE carriage on discharge the average number of antibiotics prescribed was significantly higher than in patients with no-ESBL-PE carriage (1.7 vs 0.9 ; p- 
Table 1: ESBL carriage rate on admission and discharge as a function of age group

\begin{tabular}{|c|c|c|c|c|c|}
\hline \multirow[t]{2}{*}{ Age group } & \multicolumn{2}{|c|}{ On admission } & \multicolumn{2}{|c|}{ On discharge } & \multirow[t]{2}{*}{$\operatorname{RR}[95 \% \mathrm{Cl}]$} \\
\hline & $\mathbf{N}$ & ESBL + (\%) & $\mathbf{N}$ & ESBL + (\%) & \\
\hline $0-4$ years & 182 & $44(24.2)$ & 115 & $70(60.8)$ & $2.5[1.9-3.5]$ \\
\hline 5-9 years & 35 & $3(8.5)$ & 21 & $11(52.4)$ & 6.1 [1.9 - 19.4] \\
\hline$\geq 10$ years & 27 & $7(25.9)$ & 18 & $7(38.8)$ & $1.5[0.7-3.5]$ \\
\hline Total & 244 & $54(22.1)$ & 154 & $88(57.1)$ & $2.6[2.0-3.5]$ \\
\hline
\end{tabular}

value $<0.01$ ). Overall, $46.8 \%$ of patients received more than one antibiotic. The antibiotic therapy included ampicillin (38.7\%), ceftriaxon (29.4\%) and gentamicin (27.8\%). In backward stepwise logistic regression analysis, ampicillin (adjusted OR $=3.9$ [95\%CI: 1.6-9.9]) was the only antibiotic in relation with ESBL-PE acquisition (table 5).

\section{Nosocomial infections}

During the study, six hospital-acquired infections occurred among the 190 patients hospitalized for more than 48 hours. The incidence rate was estimated at 3.1\% during the study period. The major cause of infection was intravenous catheters $(n=4)$. None of the six patients were ESBL-PE carriers on admission.

K. pneumoniae $(\mathrm{n}=3)$, Pantoea sp $(\mathrm{n}=2)$, Acinetobacter baumanii $(\mathrm{n}=1)$ were isolated. All $K$. pneumoniae and Pantoea $s p$ were ESBL-PE but remained susceptible to amikacin and imipenem in all cases.

\section{Discussion}

This study aimed to evaluate the intestinal carriage of ESBL-PE in children hospitalized in the JRB Hospital of Antananarivo, to develop a preventive strategy for controlling the spread of multiresistant bacteria in the pediatric ward. Our results confirm previous findings showing high levels of gut colonization by ESBL-PE in hospitals of low-income countries [3], and raises special concerns about the community spread of these multidrug resistant bacteria in Madagascar.

On admission, a carriage rate greater than $20 \%$ suggests prior acquisition via the community. Interestingly, although history of hospitalization appeared to be a risk factor, 74.1\% of ESBL-PE carriers had not been hospitalized during the previous 30 days (Table 4), demonstrating that the community compartment is essential for the maintenance of ESBL-PE. Of the 154 patients sampled on discharge after more than 48 hours of hospitalization, the carriage rate exceeded $50 \%$. The independent risk factors associated with ESBL-PE carriage were however known.

Table 2: ESBL-producing Enterobacteria according to the different origins of the samples

\begin{tabular}{|c|c|c|c|c|c|c|c|}
\hline & $\begin{array}{r}\text { Samples } \\
\text { taken }\end{array}$ & $\begin{array}{r}\text { Positive samples } \\
\mathrm{N},(\%)\end{array}$ & $\begin{array}{r}\begin{array}{r}\text { ESBL-producing } \\
\text { strains }\end{array}\end{array}$ & $\begin{array}{r}\text { Escherichia coli } \\
\mathrm{N},(\%)\end{array}$ & $\begin{array}{r}\text { Klebsiella } \\
\text { Pneumoniae } \\
\mathrm{N},(\%)\end{array}$ & $\begin{array}{r}\text { Enterobacter } \\
\text { cloacae } \\
\mathrm{N},(\%)\end{array}$ & $\begin{array}{r}\text { Other } \\
\text { enterobacteria } \\
N,(\%)\end{array}$ \\
\hline $\begin{array}{l}\text { Patient } \\
\text { hospitalized at the } \\
\text { beginning of the } \\
\text { study }\end{array}$ & 37 & $20(54.1)$ & 20 & $8(40.0)$ & $11(55.0)$ & $1(5.0)$ & 0 \\
\hline $\begin{array}{l}\text { Patients on } \\
\text { admission }\end{array}$ & 244 & $54(22.1)$ & 65 & 24 (36.9) & 24 (36.9) & $11(16.9)$ & $6(9.2)$ \\
\hline $\begin{array}{l}\text { Patients on } \\
\text { discharge }\end{array}$ & 154 & $88(57.1)$ & 110 & $30(27.3)$ & $58(52.7)$ & $11(10.0)$ & $11(10.0)$ \\
\hline $\begin{array}{l}\text { Medical } \\
\text { Staff }\end{array}$ & 39 & $19(48.7)$ & 20 & $9(45.0)$ & $9(45.0)$ & $1(5.0)$ & $1(5.0)$ \\
\hline $\begin{array}{l}\text { Environmental } \\
\text { samples }\end{array}$ & 100 & $13(13.0)$ & 13 & $4(30.8)$ & $5(38.5)$ & $4(30.8)$ & 0 \\
\hline $\begin{array}{l}\text { Nosocomial } \\
\text { infections }\end{array}$ & 7 & $6(85.7)$ & 5 & 0 & $3(60.0)$ & 0 & $2(40.0)$ \\
\hline Total & 578 & $200(34.6)$ & 233 & $75(32.2)$ & $110(47.2)$ & $28(12.0)$ & $20(8.6)$ \\
\hline
\end{tabular}


Table 3: Antimicrobial resistance of ESBL-producing E. Coli and K. Pneumoniae isolates from community or acquired during hospitalization (number of tested isolates in brackets)

\begin{tabular}{|c|c|c|c|c|c|c|c|c|c|c|c|c|}
\hline \multicolumn{13}{|c|}{ Drugs } \\
\hline & & AMX & TIC & AMC & CAZ & GEN & TOB & AMK & IMP & NAL & CIP & TMP \\
\hline \multicolumn{13}{|c|}{ Community strains - On admission without prior hospitalization history } \\
\hline E. coli $(n=15)$ & $\%$ & 100.0 & 100.0 & 100.0 & 93.3 & 73.3 & 80.0 & 0.0 & 0.0 & 86.7 & 60.0 & 93.3 \\
\hline K.Pneumoniae $(n=15)$ & $\%$ & 100.0 & 100.0 & 100.0 & 86.7 & 80.0 & 86.7 & 0.0 & 0.0 & 40.0 & 33.3 & 93.3 \\
\hline \multicolumn{13}{|c|}{ Hospital-acquired strains - On discharge ESBL-PE negative on admission } \\
\hline E. coli $(n=19)$ & $\%$ & 100.0 & 100.0 & 100.0 & 100.0 & 94.7 & 100.0 & 0.0 & 0.0 & 94.7 & 78.9 & 89.5 \\
\hline K.Pneumoniae $(n=39)$ & $\%$ & 100.0 & 100.0 & 100.0 & 79.4 & 89.7 & 89.7 & 0.0 & 0.0 & 46.1 & 35.8 & 100.0 \\
\hline
\end{tabular}

Table 4: Analysis of the risk factors on admission

\begin{tabular}{|c|c|c|c|c|c|c|}
\hline & \multicolumn{2}{|c|}{ Total $(n=244)$} & \multicolumn{2}{|c|}{$E S B L+(n=54)$} & \multirow[b]{2}{*}{ OR } & \multirow[b]{2}{*}{ p-value } \\
\hline & $\mathbf{N}$ & (\%) & $\mathbf{N}$ & (\%) & & \\
\hline \multicolumn{7}{|l|}{ Sex } \\
\hline Male & 136 & $(55.7)$ & 32 & $(59.2)$ & 1.3 & 0.5 \\
\hline \multicolumn{7}{|l|}{ Age group (months) } \\
\hline$<1$ & 31 & $(12.7)$ & 6 & $(11.1)$ & & 0.31 \\
\hline 1 to 12 & 84 & (34.4) & 25 & $(46.3)$ & & \\
\hline 13 to 24 & 37 & $(15.2)$ & 8 & $(14.8)$ & & \\
\hline 25 to 35 & 22 & (9.0) & 4 & (7.5) & & \\
\hline$\geq 36$ & 70 & $(28.7)$ & 11 & $(20.3)$ & & \\
\hline Mean age $[95 \% \mathrm{Cl}]$ & 35.6 & {$[29.7-41.6]$} & 33.3 & {$[19.2-47.4]$} & & 0.86 \\
\hline \multicolumn{7}{|l|}{ Patient origin } \\
\hline House & 73 & $(29.9)$ & 15 & $(27.8)$ & & 0.2 \\
\hline Primary Health centre & 149 & $(61.0)$ & 31 & $(57.4)$ & & \\
\hline Other unit or hospital & 22 & (9.0) & 8 & $(14.8)$ & & \\
\hline \multicolumn{7}{|l|}{ Last 30 days history } \\
\hline Hospitalization & 23 & (9.4) & 14 & $(25.9)$ & 7.4 & $<0.01$ \\
\hline Invasives devices used & 15 & $(6.1)$ & 11 & $(20.3)$ & 10.8 & $<0.01$ \\
\hline Antibiotic therapy & 100 & $(40.9)$ & 22 & $(40.7)$ & 1.0 & 0.9 \\
\hline \multicolumn{7}{|l|}{ Admitting diagnoses } \\
\hline Respiratory & 84 & $(31.5)$ & 19 & $(35.2)$ & 0.8 & 0.5 \\
\hline Digestive & 39 & $(12.3)$ & 9 & $(16.6)$ & & \\
\hline Malnutrition & 37 & $(15.2)$ & 10 & $(18.5)$ & & \\
\hline Neurological & 49 & $(20.1)$ & 8 & $(14.8)$ & & \\
\hline Infection upon admission & 51 & $(20.9)$ & 19 & $(37.3)$ & 1.3 & $<0.01$ \\
\hline
\end{tabular}


Table 5: Analysis of the risk factors during hospitalization

\begin{tabular}{|c|c|c|c|c|c|c|c|}
\hline & \multicolumn{2}{|c|}{ Total $(n=120)$} & \multicolumn{2}{|c|}{ ESBL-PE Carriage $(n=57)$} & \multirow[b]{2}{*}{ OR } & \multirow[b]{2}{*}{$95 \% \mathrm{Cl}$} & \multirow[b]{2}{*}{ p-value } \\
\hline & $\mathbf{n}$ & (\%) & $\mathbf{n}$ & (\%) & & & \\
\hline \multicolumn{8}{|l|}{ Hospitalization treatments } \\
\hline Antibiotics & 77 & $(64.2)$ & 45 & $(78.9)$ & 3.5 & {$[1.5-5.9]$} & $<0.01$ \\
\hline Intracranial catheter & 38 & $(31.7)$ & 22 & $(38.6)$ & 1.9 & {$[0.9-4.4]$} & 0.08 \\
\hline Brachial catheter & 20 & $(16.7)$ & 13 & $(22.8)$ & 2.3 & {$[0.8-6.4]$} & 0.1 \\
\hline intramuscular injection & 36 & $(30.0)$ & 24 & $(42.1)$ & 3.1 & {$[1.4-7.2]$} & $<0.01$ \\
\hline intravenous injection & 10 & (8.3) & 4 & $(7.0)$ & 0.7 & {$[0.2-2.7]$} & 0.5 \\
\hline Nasogastric sond & 30 & $(25.0)$ & 16 & $(28.1)$ & 1.1 & {$[0.7-1.7]$} & 0.7 \\
\hline \multicolumn{8}{|l|}{ Moving in unit } \\
\hline rooms & 35 & $(29.2)$ & 17 & $(29.8)$ & 0.95 & {$[0.6-1.4]$} & 0.7 \\
\hline care rooms & 107 & $(89.2)$ & 54 & $(94.7)$ & 1.01 & {$[0.6-1.8]$} & 0.9 \\
\hline \multicolumn{8}{|l|}{ Care rooms used } \\
\hline Ground floor & 7 & (5.8) & 6 & $(10.5)$ & 3.63 & {$[0.6-22.4]$} & 0.1 \\
\hline First floor & 40 & (33.3) & 18 & $(31.6)$ & 1.4 & {$[0.4-5.5]$} & 0.5 \\
\hline Second floor & 60 & $(50.0)$ & 30 & (31.6) & 1.3 & {$[0.3-5.9]$} & 0.9 \\
\hline
\end{tabular}

Thus, previously hospitalized patients receiving antibiotic therapy, especially ampicillin, are the patients most likely to be affected. Additional risk results from placement of indwelling devices (catheters). Moreover, 48.7\% healthy medical staffs were carriers, and, $22 \%$ of the environmental samples were positive, indicating poor hospital hygiene.

Swabs were plated on Drigalski agar supplemented with $3 \mathrm{mg} /$ liter ceftriaxon; this led to the selection of not only ESBL-PE, but also to all GNB resistant to third generation cephalosporins, including non-fermentative species as $P$. aeruginosa or Acinetobacter baumannii. Although the recommended selective media is Drigalski agar supplemented with cefotaxime $0.5 \mathrm{mg} /$ liter or MacConkey agar supplemented with ceftazidime $4 \mathrm{mg} /$ liter, ceftriaxone was chosen, as it is the only third generation cephalosporin available in Madagascar. The concentration of 3 $\mathrm{mg} /$ liter was adjusted by pretesting, to improve specificity of the screening. It is therefore likely that the true prevalence rates of ESBL-PE carriage were higher than those found, already well above the rates reported elsewhere. Conversely, studies conducted from 1993 to 1997 in Finland [13] or from 1997 to 1999 in Spain [14] showed that stool cultures contained no ESBL-producing isolates when performed on antibiotic-free agar plates.

A weakness of the study was that we were unable to sample all of the patients on discharge, diminishing the strength of the statistical analysis. However, the rate of $50 \%$ for ESBL-PE carriage on discharge, in a non epi- demic context, matched well that of inpatients sampled at the beginning of the study.

Asymptomatic colonization of the intestinal mucosa with ESBL-producing GNB has been previously described [15-17]. Several surveys, conducted during nosocomial infection outbreaks, revealed the spread of multiresistant strains within the ward, including the spread to other wards of the hospital due to transmission from patients to others or from staff to patients. In our study, we were not able to determine the relatedness between ESBL-PE from different origins, but the origins are probably various. Rates of ESBL-PE carriage among hospitalized patients were estimated at $11.7 \%$ in Spain [18], 16\% in Lebanon [19], and 26\% in Saudi Arabia [20]. A previous prospective study of children in Turkey revealed that $18.5 \%$ of children carry ESBL-producing $K$. pneumoniae, the incidence rate of nosocomial infections due to this strain being $1.6 \%$ among hospitalized children [21].

The rate of $22.1 \%$ of ESBL-PE carriage on admission to the pediatric ward in Antananarivo, largely exceeds that reported from an intensive care unit in a hospital in Baltimore (2\%) [22], and from a neonatal intensive care unit in Washington (4.2\%) [23]. All these findings and those of outpatients in Barcelona, Spain (7.5\%) [4] raise the question of asymptomatic carriage of ESBL-PE in the community [7], which enhances the spread of resistance genes by human-to-human transmission or contamination of the environment [24,25]. Such a hidden reserve of resistance 
Table 6: Analysis of the Antibiotic therapies

\begin{tabular}{|c|c|c|c|c|c|c|}
\hline \multirow[t]{2}{*}{ ESBL-PE carriage } & \multicolumn{3}{|c|}{ Univariate } & \multicolumn{3}{|l|}{ Multivariate } \\
\hline & OR & $95 \% \mathrm{Cl}$ & p-value & OR adjusted & $95 \% \mathrm{Cl}$ & p-value \\
\hline Ampicillin & 3.9 & {$[1.6-9.9]$} & $<0.01$ & 3.5 & {$[1.4-9.2]$} & $<0.01$ \\
\hline Gentamicin & 2.4 & {$[1.1-5.6]$} & 0.04 & 2.0 & {$[0.7-5.3]$} & 0.15 \\
\hline Ceftriaxone & 2.0 & {$[0.8-4.4]$} & 0.09 & 1.2 & {$[0.5-3.2]$} & 0.65 \\
\hline
\end{tabular}

factors carried by healthy people may help to maintain high levels of antimicrobial resistance in hospital floras $[26,27]$. Under antibiotic selective pressure, especially in intensive care units [28], intestinal colonization by ESBLPE strains is favored among inpatients, increasing the carriage rates and the risk of nosocomial infections $[29,30]$. First-line antibiotic therapies for the treatment of these infections, such as amikacin and imipenem, are expensive and difficult to acquire in Madagascar. Most ESBL-PE isolates are multidrug-resistant strains. Only $54.3 \%$ of isolates were susceptible to fluoroquinolones (FQ) on admission, and $47.8 \%$, on discharge (Table 6). Previous FQ consumption has been proven to be a risk factor for acquisition of ESBL-producing strains, especially those producing CTX-M-type enzymes [29,31].

The significant increase in the prevalence of ESBL-PE carriage raises the concern of multidrug resistance in Madagascar. The presence of ESBL-PE complicates the selection of antibiotics used for the empirical therapy of community-onset infections. The only effective treatment for these strains (carbapenem and amikacin) (table 3) are not available in Madagascar, as they are too expensive. We fear that the increasing use of broad spectrum antibiotics may lead to an increased incidence of infections with ESBL-PE, whose treatment will be increasingly difficult. There is an urgent need to promote a rational use of antibiotics, both in hospital and in the community, the development of new generic drugs, and strict personal hygiene to prevent the selection and the spread of these strains.

\section{Conclusions}

Nosocomial infections and antimicrobial resistance have become increasing challenges in low-income countries. The detection and quarantine of patients with ESBL-PE on admission to hospital are no longer adequate measures if a significant rate of carriage is highlighted in the community. Further studies are needed to quantify the prevalence of ESBL-PE carriage in the Malagasy population and to identify its determinants. The epidemic spread of resistance factors knows no borders. International collaboration is needed to help developing countries respond to the threat of infection with multidrug resistant bacteria.
This study was supported by a grant from the Institut Pasteur of Madagascar.

\section{Conflicts of interest}

The authors declare that they have no competing interests.

\section{Note}

Two First authors:

Dr Andriatahina is a physician. She had working in the Epidemiology Unit at the Institut Pasteur de Madagascar to validate MdH of IFMT (Laos).

Dr Randianirina has conducted biological research in Pasteur Institute of Madagascar for 5 years. She led the bacteriological analysis of this work.

These two authors contributed equally to this study

\section{Authors' contributions}

TA participated in the planning and execution of the study, performed data entry and data analysis, and was the principal investigator, FR performed the laboratory work. AT participated in the planning of the study, provided advices and participated in writing. HR was involved in planning the study. YB participated in data analysis and writing, and VR was the project coordinator and participated in planning, data analysis and writing. All authors read and approved the manuscript

\section{Author Details}

1Hôpital Joseph Raseta Befelatanana, Antananarivo, Madagascar, 2Institut Pasteur, Antananarivo, Madagascar and ${ }^{3}$ Institut de la Francophonie pour la Médecine Tropicale, Ventiane, Laos

Received: 2 July 2009 Accepted: 12 July 2010

Published: 12 July 2010

\section{References}

1. Bradford PA: Extended-spectrum beta-lactamases in the 21st century: characterization, epidemiology, and detection of this important resistance threat. Clin Microbiol Rev 2001, 14:933-51.

2. Livermore DM: Beta-lactamases in laboratory and clinical resistance. Clin Microbiol Rev 1995, 8:557-584.

3. Pitout JDD, Laupland KB: Extended-spectrum beta-lactamaseproducing Enterobacteriaceae: an emerging public-health concern. Lancet Infect Dis 2008, 8:159-166.

4. Mirelis B, Navarro F, Miro E, Mesa RJ, Coll P, Prats G: Community transmission of extended-spectrum beta-lactamase. Emerg Infect Dis 2003, 9:1024-1025.

5. Paterson DL, Yu VL: Extended-spectrum beta-lactamases: a call for improved detection and control. Clin Infect Dis 1999, 29:1419-1422.

6. Castillo Garcia FJ, Seral Garcia C, Pardos De la Gandara M, Millan Lou MI, Pitart Ferre C: Prevalence of fecal carriage of ESBL-producing Enterobacteriaceae in hospitalized and ambulatory patients during two non-outbreak periods. Eur J Clin Microbiol Infect Dis 2007, 26:77-78. 
7. Smith DL, Dushoff J, Perencevich EN, Harris AD, Levin SA: Persistent colonization and the spread of antibiotic resistance in nosocomial pathogens: resistance is a regional problem. Proc Natl Acad Sci USA 2004, 101:3709-3714.

8. Blomberg B, Jureen R, Manji KP, Tamim BS, Mwakagile DSM, Urassa WK Fataki M, Msangi V, Tellevik MG, Maselle SY, Langeland N: High rate of fatal cases of pediatric septicemia caused by gram-negative bacteria with extended-spectrum beta-lactamases in Dar es Salaam, Tanzania. $J$ Clin Microbiol 2005, 43:745-749.

9. Sehgal R, Gaind R, Chellani H, Agarwal P: Extended-spectrum beta lactamase-producing gram-negative bacteria: clinical profile and outcome in a neonatal intensive care unit. Ann Trop Paediatr 2007 27:45-54

10. Randrianirina F, Soares J, Carod J, Ratsima E, Thonnier V, Combe P, Grosjean P, Talarmin A: Antimicrobial resistance among uropathogens that cause community-acquired urinary tract infections in Antananarivo, Madagascar. J Antimicrob Chemother 2007, 59:309-312.

11. Randrianirina F, Vaillant L, Ramarokoto Ce, Rakotoarijaona A Andriamanarivo Ml, Razafimahandry Hc, Randrianomenjanahary J, Raveloson Jr, Ratsima Hariniaina E, Carod JF, Talarmin A, Richard V: Antimicrobial resistance in pathogens causing nosocomial infections in surgery and intensive care wards of two hospitals in Antananarivo, Madagascar. JIDC 2010, 4(2):74-82.

12. Jarlier V, Nicolas MH, Fournier G, Philippon A: Extended broad-spectrum beta-lactamases conferring transferable resistance to newer betalactam agents in Enterobacteriaceae: hospital prevalence and susceptibility patterns. Rev Infect Dis 1988, 10:867-878.

13. Osterblad M, Hakanen A, Manninen R, Leistevuo T, Peltonen R, Meurman $\mathrm{O}$, Huovinen P, Kotilainen P: A between-species comparison of antimicrobial resistance in Enterobacteria in fecal flora. Antimicrob Agents Chemother 2000, 44:1479-1484.

14. Brinas L, Zarazaga M, Saenz Y, Ruiz-Larrea F, Torres C: Beta-lactamases in ampicillin-resistant Escherichia Coli isolates from foods, humans, and healthy animals. Antimicrob Agents Chemother 2002, 46:3156-3163.

15. Pena C, Pujol M, Ardanuy C, Ricart A, Pallares R, Linares J, Ariza J, Gudiol F: Epidemiology and successful control of a large outbreak due to Klebsiella Pneumoniae producing extended-spectrum beta-lactamases. Antimicrob Agents Chemother 1998, 42:53-58.

16. Hollander R, Ebke M, Barck H, von Pritzbuer E: Asymptomatic carriage of Klebsiella Pneumoniae producing extended-spectrum beta-lactamase by patients in a neurological early rehabilitation unit: management of an outbreak. J Hosp Infect 2001, 48:207-213.

17. De Champs C, Sauvant MP, Chanal C, Sirot D, Gazuy N, Malhuret R, Baguet JC, Sirot J: Prospective survey of colonization and infection caused by expanded-spectrum-beta-lactamase-producing members of the family Enterobacteriaceae in an intensive care unit. J Clin Microbio/ 1989, 27:2887-2890.

18. Valverde A, Coque TM, Sanchez-Moreno MP, Rollan A, Baquero F, Canton $R$ : Dramatic increase in prevalence of fecal carriage of extendedspectrum beta-lactamase-producing Enterobacteriaceae during nonoutbreak situations in Spain. J Clin Microbiol 2004, 42:4769-4775.

19. Moubareck C, Daoud Z, Hakime NI, Hamze M, Mangeney N, Matta H, Mokhbat JE, Rohban R, Sarkis DK, Doucet-Populaire F: Countrywide spread of community- and hospital-acquired extended-spectrum beta-lactamase (ctx-m-15)-producing Enterobacteriaceae in Lebanon. J Clin Microbiol 2005, 43:3309-3313.

20. Kader AA, Kumar A, Kamath KA: Fecal carriage of extended-spectrum beta-lactamase-producing Escherichia Coli and Klebsiella Pneumoniae in patients and asymptomatic healthy individuals. Infect Control Hosp Epidemiol 2007, 28:1114-1116.

21. Demir S, Soysal A, Bakir M, Kaufmann ME, Yagci A: Extended-spectrum beta-lactamase-producing Klebsiella Pneumoniae in paediatric wards: a nested case-control study. J Paediatr Child Health 2008, 44:548-553.

22. Harris AD, Nemoy L, Johnson JA, Martin-Carnahan A, Smith DL, Standiford $H$, Perencevich EN: Co-carriage rates of vancomycin-resistant enterococcus and extended-spectrum beta-lactamase-producing bacteria among a cohort of intensive care unit patients: implications for an active surveillance program. Infect Control Hosp Epidemiol 2004, 25:105-108.

23. Singh N, Patel KM, Leger M, Short B, Sprague BM, Kalu N, Campos JM: Risk of resistant infections with Enterobacteriaceae in hospitalized neonates. Pediatr Infect Dis J 2002, 21:1029-1033.
24. Levin BR: Minimizing potential resistance: a population dynamics view. Clin Infect Dis 2001, 33(Suppl 3):S161-9.

25. Canton R, Coque TM, Baquero F: Multi-resistant gram-negative bacilli: from epidemics to endemics. Curr Opin Infect Dis 2003, 16:315-325.

26. Lipsitch M, Samore MH: Antimicrobial use and antimicrobial resistance: a population perspective. Emerg Infect Dis 2002, 8:347-354.

27. Bonten MJ, Slaughter S, Ambergen AW, Hayden MK, van Voorhis J, Nathan C, Weinstein RA: The role of "colonization pressure" in the spread of vancomycin-resistant enterococci: an important infection control variable. Arch Intern Med 1998, 158:1127-1132.

28. Green M, Barbadora K: Recovery of ceftazidime-resistant Klebsiella Pneumoniae from pediatric liver and intestinal transplant recipients. Pediatr Transplant 1998, 2:224-230.

29. Wiener J, Quinn JP, Bradford PA, Goering RV, Nathan C, Bush K, Weinstein RA: Multiple antibiotic-resistant Klebsiella and Escherichia Coli in nursing homes. JAMA 1999, 281:517-523.

30. Trick WE, Weinstein RA, DeMarais PL, Kuehnert MJ, Tomaska W, Nathan C, Rice TW, McAllister SK, Carson LA, Jarvis WR: Colonization of skilled-care facility residents with antimicrobial-resistant pathogens. J Am Geriatr Soc 2001, 49:270-276.

31. Rodriguez-Bano J, Navarro MD, Romero L, Martinez-Martinez L, Muniain MA, Perea EJ, Perez-Cano R, Pascual A: Epidemiology and clinical features of infections caused by extended-spectrum beta-lactamase-producing Escherichia Coli in nonhospitalized patients. J Clin Microbiol 2004, 42:1089-1094.

\section{Pre-publication history}

The pre-publication history for this paper can be accessed here: http://www.biomedcentral.com/1471-2334/10/204/prepub

doi: 10.1186/1471-2334-10-204

Cite this article as: Andriatahina et al., High prevalence of fecal carriage of extended-spectrum ?-lactamase-producing Escherichia coli and Klebsiella pneumoniae in a pediatric unit in Madagascar BMC Infectious Diseases 2010, $10: 204$

\section{Submit your next manuscript to BioMed Central and take full advantage of:}

- Convenient online submission

- Thorough peer review

- No space constraints or color figure charges

- Immediate publication on acceptance

- Inclusion in PubMed, CAS, Scopus and Google Scholar

- Research which is freely available for redistribution 